\title{
PSD Analysis and Optimization of 2500hp Shale Gas Fracturing Truck Chassis Frame
}

\author{
Han-Xiang Wang, De-Xin Yuan, Li-Jun Zhang ${ }^{*}$ and Fan Zhang
}

School of Mechanical and Electrical Engineering, China University of Petroleum, Qingdao, Shandong, 266580, P.R. China

\begin{abstract}
The three-dimensional model of $2500 \mathrm{hp} \mathrm{shale} \mathrm{gas} \mathrm{fracturing} \mathrm{truck} \mathrm{chassis} \mathrm{frame} \mathrm{was} \mathrm{established} \mathrm{and} \mathrm{the}$ natural frequency of the frame was obtained by modal analysis. Taking the displacement power spectrum density of a typical road as a random excitation, the random vibration response of frame was obtained by PSD module of finite element analysis software ANSYS. Based on the results of PSD analysis, the frame's fatigue characteristic under random vibration condition was studied according to Gauss distribution theory and Miner fatigue cumulative damage law, and the random fatigue strength of the frame was also calculated and optimized as well. A reliable and practical method was provided to verify the fatigue strength and to predict fatigue life of fracturing truck chassis frame. The conclusion provides an important theoretical reference for optimization of the frame.
\end{abstract}

Keywords: Fatigue strength, finite element analysis, fracturing truck, random vibration, shale gas.

\section{INTRODUCTION}

With the accelerating development of shale gas exploitation, the designing and manufacturing of fracturing equipment with high pressure and large delivery capacity has entered into a rapid development stage. $2500 \mathrm{hp}$ shale gas fracturing truck, with installed power of $3000 \mathrm{hp}$, maximum pressure of $140 \mathrm{Mpa}$, and curb weight $45 \mathrm{t}$ or more, can meet various requirements of deep well exploitation in China. However, road surface with the poor conditions will generate random excitation to the truck chassis frame when it runs on road. When the stress level is high and keeping for a certain working hours, random fatigue damages may suddenly occur, which results in huge losses and serious consequences [1-3]. Therefore, forecasting random fatigue life span of heavy truck chassis frame is extremely necessary.

\section{DESCRIPTION OF RANDOM VIBRATION EXCITATION}

During the fracturing truck running, the frame would produce displacement in the direction of perpendicular to the road surface because of the uneven terrain. The actual smooth degree of road is various and changing, therefore the excitation caused by road can be regarded as random to the frame, which leads the frame to produce random vibration. Random vibration can not be described by deterministic time function, but it is always described by probability and statistics method, benefiting from the existence of a certain statistical rule. A large number of experiments and studies have shown that the road roughness is a stationary Gaussian random process with zero-mean and ergodic properties [4]. During engineering practice, it is common to describe the statistic characteristic of road rough degree by road power spectrum. According to the actual situation of roads in China, the road power spectral density can be expressed as [5]:

$$
G_{q}(n)=G_{q}\left(n_{0}\right)\left(\frac{n}{n_{0}}\right)^{-\omega}
$$

where $n$ is the spatial frequency $\left(m^{-1}\right)$, and is the number of wavelength in unit traveling distance; $n_{0}=0.1 \mathrm{~m}^{-1}$, is the spatial frequency; $G_{q}\left(n_{0}\right)$ is the road surface roughness coefficient, which is the road power spectral density under the reference spatial frequency $n_{0} ; \omega$ is the frequency index, and is frequency structure of road power spectral density, commonly, $\omega=2$.

The smooth degree of road surface can be ranked into 8 levels according to the road surface roughness coefficient. Road surface with A level is smoothest and road surface with $\mathrm{H}$ level is roughest. Table $\mathbf{1}$ shows the relevant parameter of E level road.

Table 1. E-level road roughness power spectral density.

\begin{tabular}{|c|c|c|c|}
\hline \multirow{2}{*}{ Road Level } & \multicolumn{3}{|c|}{$G_{q}\left(\boldsymbol{n}_{\mathbf{0}}\right) \times \mathbf{1 0}^{-\mathbf{6}} \mathbf{m}^{\mathbf{2}} / \mathbf{m}^{\mathbf{- 1}} ; \boldsymbol{n}_{\mathbf{0}}=\mathbf{0 . 1}^{-\mathbf{1}}$} \\
\cline { 2 - 4 } & Lower Limit & Geometric Mean & Upper Limit \\
\hline \hline $\mathrm{E}$ & 2048 & 4096 & 8192 \\
\hline
\end{tabular}

When the fracturing truck runs at the speed of $u$ on the road with the spatial frequency of $n$, spatial frequency power spectral density can be transformed into temporal frequency power spectral density. The conversion relationship between temporal frequency with spatial frequency is $f=u n$, so the conversion relationship between $G_{q}(n)$ and $G_{q}(f)$ is: 
$G_{q}(f)=\frac{1}{u} G_{q}\left(n_{0}\right)\left(\frac{n}{n_{0}}\right)^{-2}=G_{q}\left(n_{0}\right) n_{0}^{2} \frac{u}{f^{2}}$

Road power spectral density describes the distribution of road surface roughness average square value on view of frequency domain, and it indicates vibratory energy of unit frequency band [6]. This speed of fracturing truck is assumed to be $72 \mathrm{~km} / \mathrm{h}$ and the power spectral density of road in $\mathrm{E}$ level is used as random excitation import to analyze the random vibration. Fig. (1) shows the logarithmic coordinate road power spectral density of E-level road.

\section{PSD ANALYSIS OF TRUCK CHASSIS FRAME}

When fracturing truck running on roads, weight of upper equipment, such as engine, transmission case, and fracturing pump will apply preload to the frame. In order to consider the impact of prestressing force, the static analysis should be finished before PSD analysis. This paper uses the mode superposition method, which needs to calculate the modal of frame, to solve the random vibration equation. Static stress and modal analysis of frame have been performed by ANSYS 14.0. Table 2 shows the previous 10 steps modal results of frame with prestress.

Table 2. The first 10 steps modal analysis results of the frame.

\begin{tabular}{|c|c|c|c|c|c|}
\hline Step & $\mathbf{1}$ & $\mathbf{2}$ & $\mathbf{3}$ & $\mathbf{4}$ & $\mathbf{5}$ \\
\hline \hline Frequency $(\mathrm{Hz})$ & 16.679 & 24.126 & 30.200 & 35.006 & 41.494 \\
\hline Step & $\mathbf{6}$ & $\mathbf{7}$ & $\mathbf{8}$ & $\mathbf{9}$ & $\mathbf{1 0}$ \\
\hline \hline Frequency $(\mathrm{Hz})$ & 46.574 & 47.134 & 53.496 & 58.976 & 67.110 \\
\hline
\end{tabular}

\subsection{PSD Analysis Process}

PSD analysis is also called random vibration analysis. Using PSD module of finite element analysis software ANSYS to analyze random vibration, it includes six main procedures: modeling; modal analysis; expand modes; spectrum analysis; mode combine; and observations [7]. Random excitation will be defined by "spectral valuefrequency" two-dimensional table and the power spectral density value includes displacement, velocity, acceleration, force and so on.

The results of PSD analysis mainly include the stress of every nodes and $1 \sigma$ response value, which is a statistic concept, indicating the average response square value of a certain parameter under normal distribution. The probability of an arbitrary response value, lower than $1 \sigma$ response value is $68.3 \%$ [8]. The $1 \sigma$ displacement, velocity and acceleration power spectral density response value can be obtained from POST processor module of ANSYS.

\subsection{Results of PSD Analysis}

By means of ANSYS14.0, considering road surface roughness power spectral density as random excitation, the stress and deformation caused by random vibration can be obtained when $2500 \mathrm{hp}$ fracturing truck runs on test condition. Fig. (2a, b) shows the $1 \sigma$ stress and deformation distribution.

Fig. (2) shows that the maximal $1 \sigma$ stress of the frame is $81.1 \mathrm{Mpa}$ and it is located in the junction between rear suspension and main frame. Overall, the stress of front and rear suspension is greater than other parts, while the stress of middle part of frame is lower. It is because that road random excitation is mainly transmitted through suspension toward frame. The maximal deformation is $1.79 \mathrm{~mm}$, locating in the tail end of frame. Fracturing pump and piping system are located in tail end, so the maximal deformation locating in this part with the heaviest weight is consistent with the actual situation.

\subsection{Solution of the Dynamic Response}

The displacement, velocity, acceleration power spectral density response value of every node under random vibration can be calculated further by using ANSYS14.0. Fig. (3) shows displacement, velocity, acceleration power spectral density response graph at the maximal amplitude position.

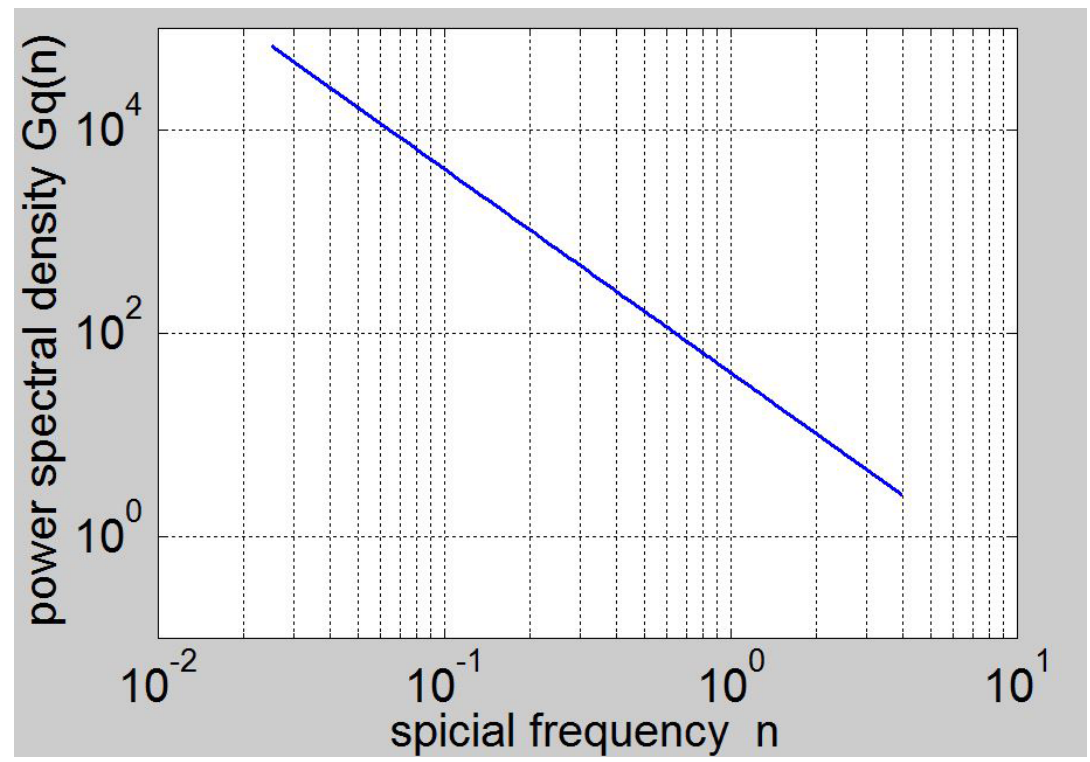

Fig. (1). Logarithmic coordinate of E-level road power spectral density. 


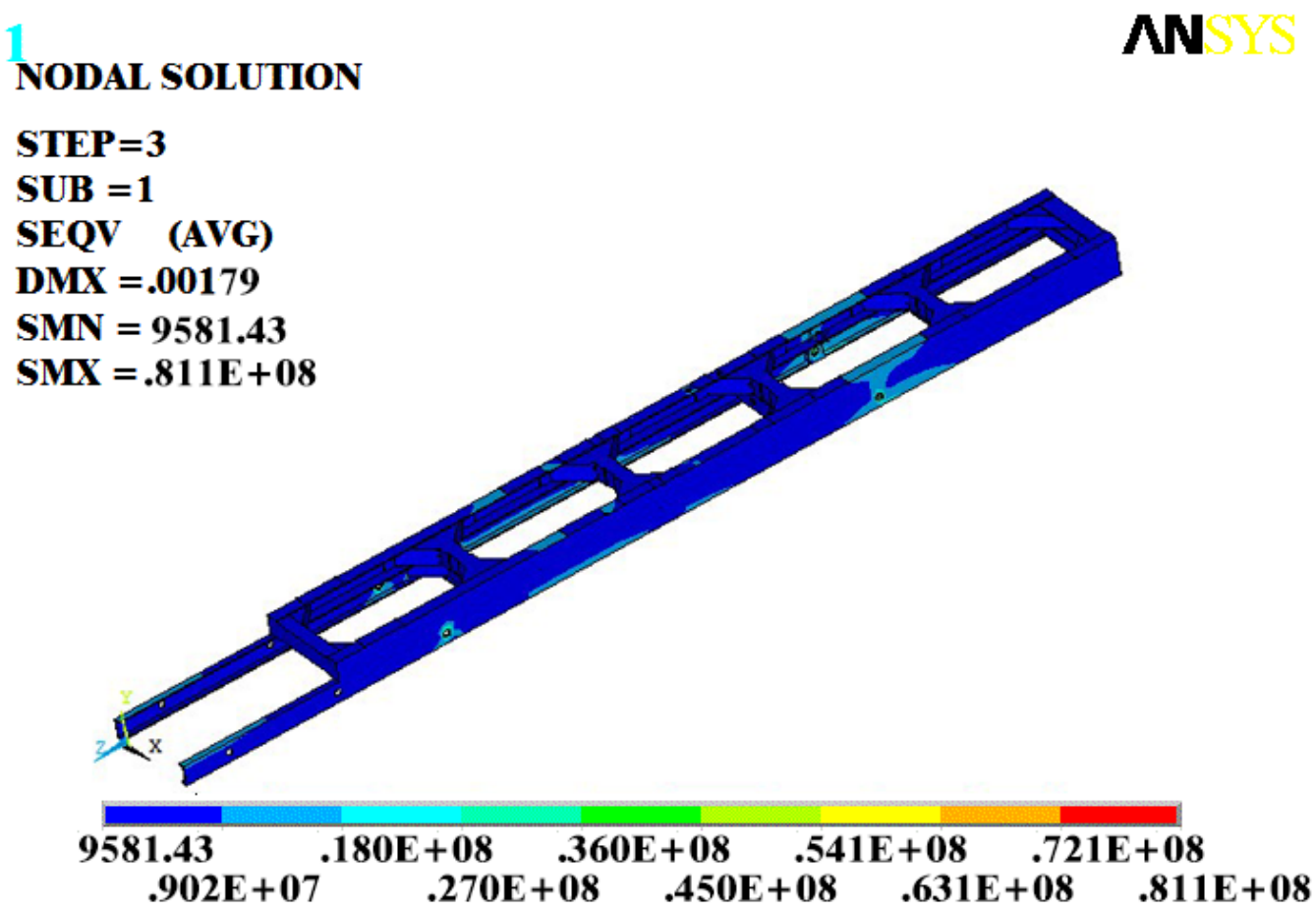

Fig. (2a). $1 \sigma$ stress distribution under random vibration.

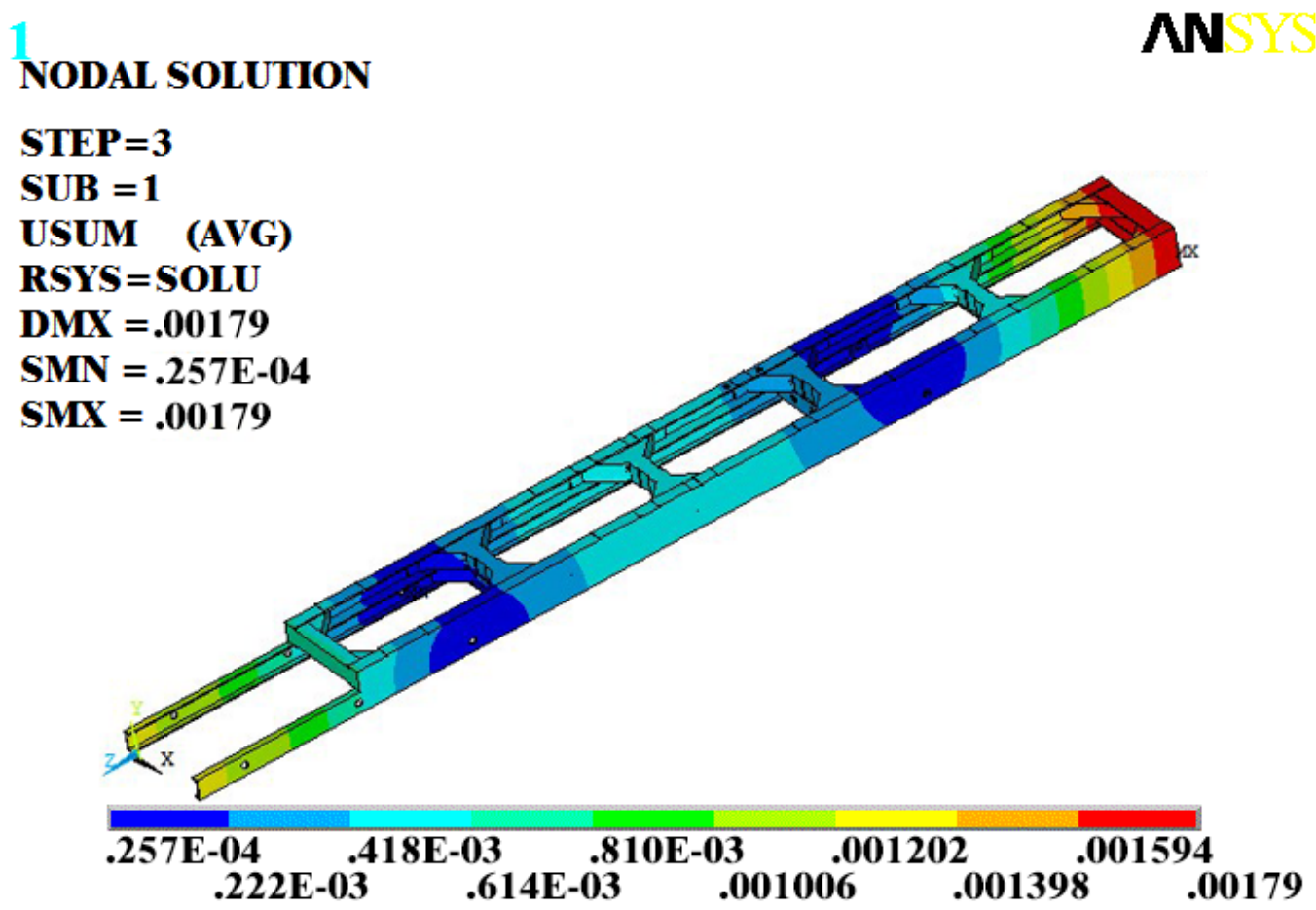

Fig. (2b). $1 \sigma$ deformation distribution under random vibration.

It can be seen from Fig. (3) that the maximal amplitude of frame occurs at the frequency of $16.679 \mathrm{~Hz}$. Displacement, velocity and acceleration response value reach to step peak at the frequency of $16.679 \mathrm{~Hz}$ and $30.2 \mathrm{~Hz}$. It can also be seen from modal analysis results that the previous two frequencies happen in the first and third step inherent frequency of the frame. Therefore, it should be considered seriously to avoid working frequency or inherent frequency of upper equipment such as fracturing pump or engine equaling or approximating to the first or third step inherent frequency of frame, avoiding resonating or causing the frame failure.

\section{THE FATIGUE ANALYSIS OF TRUCK CHASSIS FRAME}

Under the effect of random excitation from road surface, the random fatigue failure of the frame would occur. 


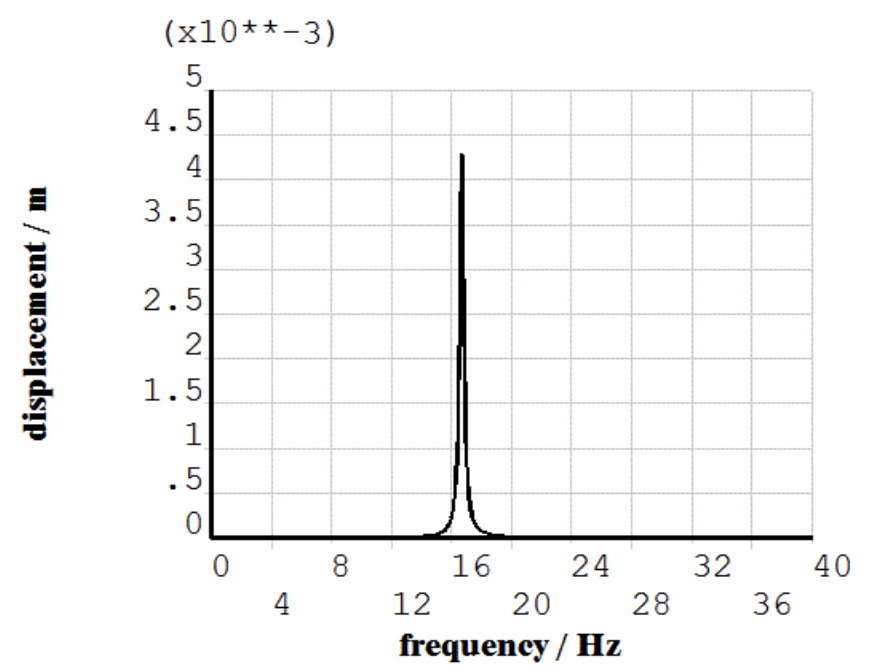

Fig. (3a). The displacement response spectrum at the maximum amplitude position.

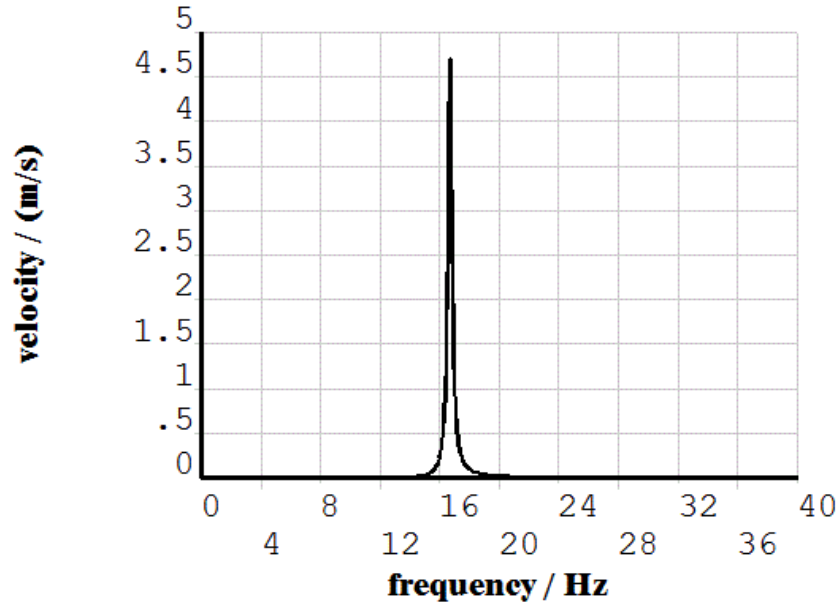

Fig. (3b). The velocity response spectrum at the maximum amplitude position.

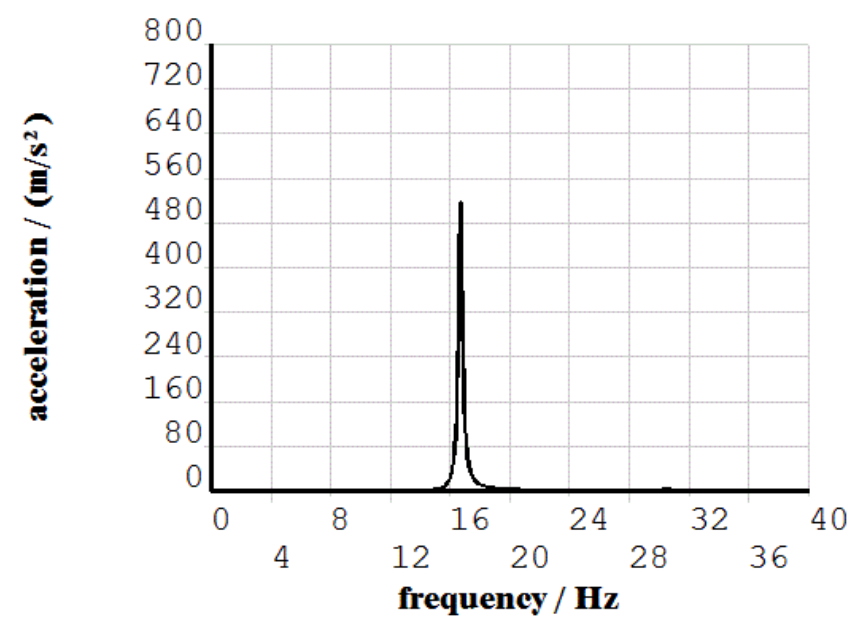

Fig. (3c). The acceleration response spectrum at the maximum amplitude position.

According to Miner fatigue cumulative damage law, each random vibration would contribute to the whole failure. When the cumulative damage reaches 100 percent, it means that the structure produces fatigue failure [9]. By this theory, the random spectrum should be transferred into the typical load spectrum or the typical power spectrum. A great deal of measurements and researches have shown that both the random excitation of road surface and the vibration response of the frame obey the normal distribution. Therefore, this paper would adopt three interval method proposed by Steinberg based on Gauss distribution theory and Miner fatigue cumulative damage law to calculate random fatigue strength of the frame based on the PSD analysis.

According to the feature of normal distribution, the stress is processed into three levels of stresses, which are $1 \sigma, 2 \sigma$ and $3 \sigma$ stresses. The probability of $1 \sigma$ is $68.3 \%$, the probability of $2 \sigma$ is $27.1 \%$, and the probability of $3 \sigma$ is $4.33 \%$. Apart from these three levels, the probability of stress is just $0.27 \%$, and it is assumed that it would not do harm to the frame. According to three interval law of Miner, the computational formula of damage would be expressed as:

$D=\frac{n_{1 \sigma}}{N_{1 \sigma}}+\frac{n_{2 \sigma}}{N_{2 \sigma}}+\frac{n_{3 \sigma}}{N_{3 \sigma}}$

where $n_{1 \sigma}$ is actual circulation number $\left(0.683 v_{0}^{+} T\right)$ of stress which is equal to or less than $1 \sigma, n_{2 \sigma}$ is actual circulation number $\left(0.27 v_{0}^{+} T\right)$ of stress which is equal to or less than $2 \sigma$, and $n_{3 \sigma}$ is actual circulation number $\left(0.0433 v_{0}^{+} T\right)$ of stress which is equal to or less than $2 \sigma . N_{1 \sigma} N_{2 \sigma}$ and $N_{3 \sigma}$ are license number of circles corresponding to each stress level according to the fatigue curve.

The vibration period of the frame is assumed as $T=$ $5 \times 10^{4} \mathrm{~s}$, and the average frequency of vibration is $v_{0}^{+}=25 \mathrm{~Hz}$, then

$$
\begin{aligned}
& n_{1 \sigma}=0.6831 v_{0}^{+} T=8.5375 \times 10^{5} \\
& n_{2 \sigma}=0.27 v_{0}^{+} T=3.375 \times 10^{5} \\
& n_{3 \sigma}=0.043 v_{0}^{+} T=5.375 \times 10^{4}
\end{aligned}
$$

During fatigue designation, related parameters could be obtained by checking corresponding p-S-N curve, according to demanded fraction surviving $\mathrm{p}$. The relationship of $\mathrm{p}-\mathrm{S}-\mathrm{N}$ curve with the fraction surviving of 50 percent is $\log N_{p}=$ $22.632-7.4382 \times \log \sigma$ [10]. Therefore the life span of frequency could be calculated by stress level:

when $1 \sigma=81.1 \mathrm{Mpa}, N_{1 \sigma}=2.69 \times 10^{8}=\infty$,

when $2 \sigma=162.2 \mathrm{Mpa}, N_{2 \sigma}=1.56 \times 10^{6}$, and when $3 \sigma=243.3 \mathrm{Mpa}, N_{3 \sigma}=7.64 \times 10^{4}$.

Putting the above results into formula (3), $D$ equals

$$
D=\frac{8.5375 \times 10^{5}}{\infty}+\frac{3.375 \times 10^{5}}{1.56 \times 10^{6}}+\frac{5.375 \times 10^{4}}{7.64 \times 10^{4}}=0
$$

If $D$ is less than 1 , it is considered that the frame would not produce fatigue damage [11]. The results illustrate that the fatigue strength of fracture truck could meet the basic demands when it runs on road with $\mathrm{E}$ level. 


\section{OPTIMIZATION OF THE CHASSIS FRAME}

As can be seen from previous analysis, the maximum fatigue stress of the frame structure is located in the join between rear suspension and main frame and sub-frame. Therefore, in order to promote life span of whole frame, the rear parts of the frame should be strengthened. But the frame should not be altered too much because various components are installed to the frame. After repeated attempts, the frame has been optimized through size and material. The main method of optimization includes decreasing the thickness of parts with redundant stress strength, increasing frame size near to chassis properly, adding gussets, which has no effects on use functions and adding special paint-coat on parts with weak stress strength. After optimization, the whole mass of frame structure decreases in a certain extent, and the maximum stress decreases obviously. Fig. (4) shows the $1 \sigma$ stress and deformation nephogram of the frame after optimization.

As can be seen from Fig. (4), the maximum $1 \sigma$ stress of frame is $70.5 \mathrm{MPa}$. It decreases a lot compared with frame without optimization, and the whole stress distribution and deformation tendency keep pace with the previous state. According to fatigue damage calculation method accounted in part 3 in detail, fatigue damage value of frame after optimization is figured out as $D=0.324$ which is considerably less than damage value 0.92 before optimization. It illustrates that fatigue damage degree decreases a lot after optimization, and there is considerable redundancy about fatigue strength of frame. It indicates that fatigue property of frame structure after optimization is more reliable on the same road condition.

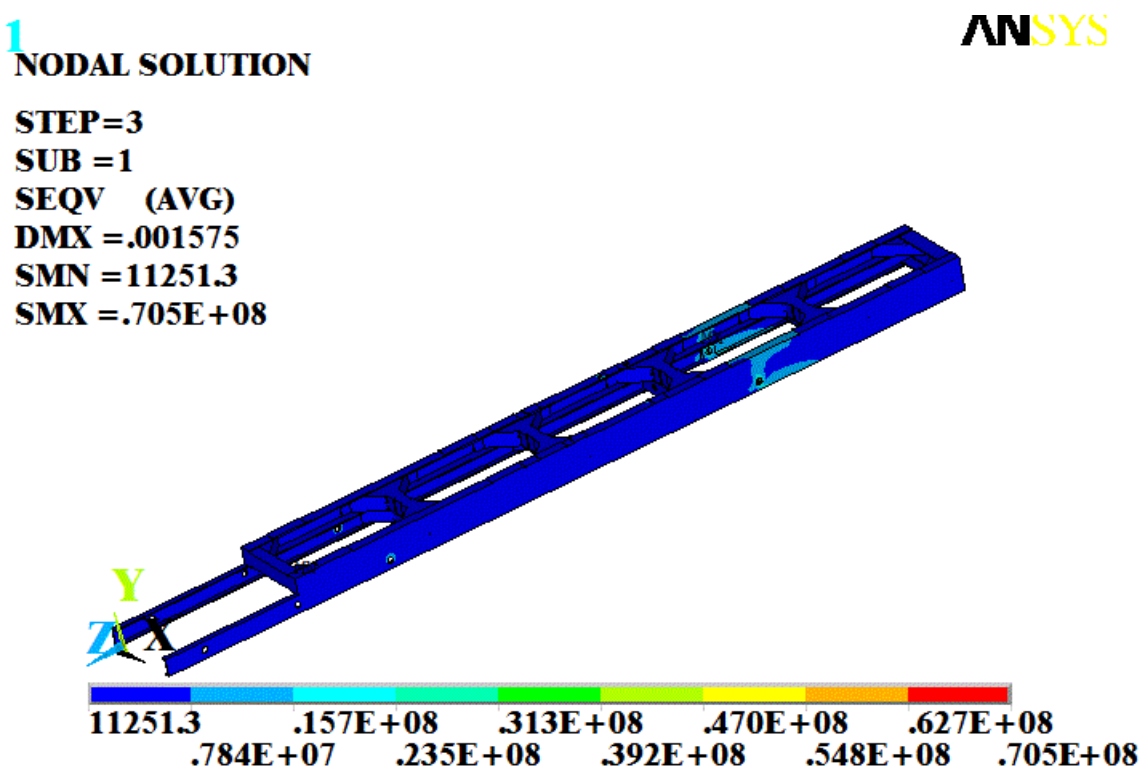

Fig. (4a). $1 \sigma$ stress distribution after optimization.

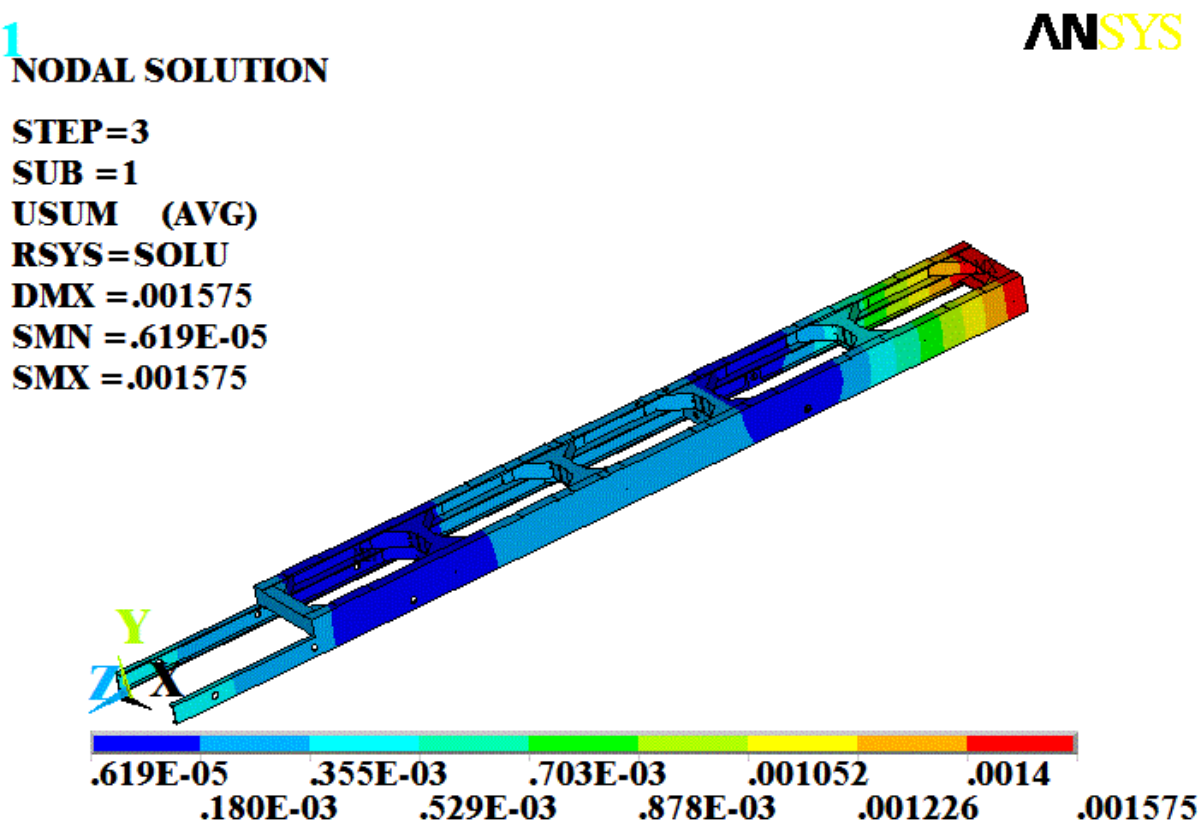

Fig. (4b). $1 \sigma$ strain distribution after optimization. 


\section{CONCLUSION}

(1) The three-dimensional model of $2500 \mathrm{hp}$ shale gas fracturing truck chassis frame was established. Static analysis and modal analysis were completed by finite element analysis software. Considering the impact of prestress, choosing E-level road surface displacement power spectral density as random excitation, the stress and deformation of frame under random vibration condition was obtained by PSD analysis.

(2) The deformation in tail frame is greater than other parts and the formation and extension of crack in this part are worthy to be noticed. Meanwhile, the strengthening design and maintenance of tail frame should be enhanced. Manufacturers can improve the whole fatigue strength of frame by using pressureproof, abrasion-proof or corrosion-resistant material at the stress concentration part.

(3) Taking advantage of Miner fatigue cumulative damage law, this article researched the fatigue characteristic of frame structure combined with related Gauss distribution theory, and then calculated random fatigue strength of frame structure based on PSD analysis results. The final results indicated that the fracturing truck frame could meet design demand of fatigue strength when it runs on $E$ level road.

(4) The frame structure is optimized. The fatigue strength and the redundancy of fatigue life span are increased after optimization.

\section{CONFLICT OF INTEREST}

The authors confirm that this article content has no conflict of interest.

\section{ACKNOWLEDGEMENTS}

The author wishes to express gratitude to the Qingdao key scientific research project development plan (Approval No. 13-4-1-2-gx), which has supported this work.

\section{REFERENCES}

[1] R. Ma, X. Wang, K. Zhang, "Random vibration fatigue analysis of bus frame", Mech. Res. Appl., vol. 1, pp. 54-56, 59, 2011.

[2] Y. Wang, J. Luo, J. Ye, L. Chen, "FEA based fatigue analysis and its application" Mach. Des. Manuf.. vol. 1, pp. 22-24, 2008.

[3] M. Sang, "The carrying capacity study of frame of the high power fracturing truck" Dalian: Dalian University of Technology master thesis, 2013.

[4] W. Schiehlen, B. Hu, "Spectral simulation and shock absorber identification", Int. J. Non-Linear Mech., vol. 38, pp. 161-171, 2003.

[5] GB/T7031-1986, vehicle vibration describing method for road surface irregularity, Beijing: Standards Press of China, 1987.

[6] J. Yin, S. Liang, C. Huang, "Static and dynamic calculation and analysis of heavy truck frame", Machinery, vol. 45, pp. 32-35, 2007

[7] He-lin Xu, Zhi-xin Han, Ji-qiang Cui, "Random vibration and fatigue strength analysis of 7140-type bus frame", J. Mach. Des., vol. 29, pp. 7-10, 2012

[8] S. Liu, D. Zhao, T. Tan, H. Liu, "The application of ANSYS in random analysis of steel-truss structure. Machinery, vol. 31, pp. 54 $55,68,2004$

[9] Y. Huang, Y. Liu, W. Liu, Z. Yue, "The analysis of dynamic reliability sensitivity for stochastic structures on the bases of fatigue damage accumulative principle”, Aircraft Des., vol. 30, pp. 5-9, 2010.

[10] P. Wang, R. Guo, W. Yuan, "Fatigue life analysis of front axle of engineering vehicle at random vibration based on numerical simulation load spectrum", Construct. Machinery Equip., vol. 44, pp. 39-42, 2013.

[11] Research on the low-cycle fatigue reliability of structure under random load, J. Machine Des., vol. 27, pp. 79-82, 2010.

(C) Wang et al.; Licensee Bentham Open.

This is an open access article licensed under the terms of the Creative Commons Attribution Non-Commercial License (http://creativecommons.org/licenses/ by-nc/3.0/) which permits unrestricted, non-commercial use, distribution and reproduction in any medium, provided the work is properly cited. 